\title{
SILOXANES REMOVAL FROM BIOGAS USING ACTIVATED CARBON
}

\author{
Alice Vagenknechtová*, Karel Ciahotný, Veronika Vrbová \\ Department of Gaseous and Solid Fuels and Air Protection, University of Chemistry and Technology Prague, \\ Prague 6, 166 28, Czech Republic \\ * corresponding author: alice.vagenknechtova@vscht.cz
}

\begin{abstract}
SiO}_{2}$ deposits which cause technical problems on combustion equipment are built by combustion of biogas containing siloxanes. Therefore, in these cases, the siloxanes must be removed from the biogas. For siloxane removal from biogas, its adsorption on activated carbon is often used. After saturation, the saturated adsorbent must be replaced. The adsorbent cost constitutes the main part of the operational costs of the purification equipment. Therefore it is necessary to find an adsorbent having high adsorption capacity for siloxane at a possible low price.

Using laboratory apparatus and biogas produced from waste-water treatment sludge at the wastewater treatment plant Prague Bubeneč various activated carbons were tested for siloxane removal and their adsorption capacities for siloxanes were estimated, and the adsorbent cost relative to $1 \mathrm{~kg}$ of siloxanes removed from biogas were calculated. The lowest price for the removal of $1 \mathrm{~kg}$ of siloxanes was determined by Chezacarb, Sil Extra 40 AP and 4-60 adsorbents. Another important information obtained from the test is that the weakly adsorbed siloxane (OMCTS) is displaced by the larger molecule of DMCPCS during adsorption.
\end{abstract}

KEYWORDS: biogas; siloxanes; adsorption.

\section{INTRODUCTION}

Biogas is produced by anaerobic fermentation of organic material in the absence of air, for example at landfills and sewage treatment plants [1]. Biogas is created by two main components, methane and carbon dioxide, and it further contains a number of minority components. Apart from methane and carbon dioxide, more than 140 other substances were identified in biogases which reach a total concentration of up to $2000 \mathrm{mg} / \mathrm{m}^{3}$ (0.15 vol\%) 2]. Biogas is most frequently used for energy purposes, i.e. for the production of electricity and heat by combustion in cogeneration units. When the composition has been treated $\left(\mathrm{CO}_{2}\right.$ separation), the biogas may be modified to so-called biomethane and used as an ecological fuel for motor vehicles [1]. Lastly, biogas also contains a high concentration of organosilicons. Organosilicon compounds are dangerous minority elements which have a negative impact on the combustion equipment in the process of the subsequent utilisation of gas for energy purposes [3].

Siloxanes are primarily used in various cosmetic products and toiletries. The worldwide use of siloxanes has been rising continuously, as these products become more and more frequently commercialized [4].

The main carriers of organosilicon substances entering biomethanation processes are wastewater sludge and solid communal waste. The name siloxanes is based on the composition of the respective compounds; these compounds contain an Si-O bonding with an organic radical attached to $\mathrm{Si}$, which includes methyl and other functional organic groups $[5]$.
Examples of siloxanes are provided in Table 13 .

Various types of volatile siloxanes have been discovered in biogas produced in the course of anaerobic digestion of organic materials, in higher concentrations than cyclic siloxanes with 4 and 5 structural units $-\mathrm{SiO}-[6]$.

The relative stability of cyclic siloxanes depends on the angle of bond within the ring. Therefore the angles of bonds in $\mathrm{Si}-\mathrm{O}-\mathrm{Si}$ and $\mathrm{O}-\mathrm{Si}-\mathrm{O}$ in dimethylsiloxanes are rather strained. Once the size of the ring exceeds 8 members $\left(D_{4}\right)$, the average angle of bond changes only minutely, as the size of the ring grows 7 .

Siloxanes are preferentially adsorbed to the so-called EPS (extracellular polymeric substances) in slurry flakes, which leads to a significant increase of their content in slurry [8]. This strong adsorptivity is illustrated by the Freundlich constant $k_{\mathrm{F}}$. For a representative molecular weight $(\mathrm{M}$ in $\mathrm{g} / \mathrm{mol})$ of 300 , the Freundlich constant is approximately 600 , which greatly exceeds the adsorption characteristics of common aliphatic or cyclic hydrocarbons [9].

Cyclic siloxanes $\mathrm{D}_{4}$ and $\mathrm{D}_{5}$ in particular can be found in biogas. Small amounts of $\mathrm{D}_{3}$ have been found in biogas and also in waste water. Larger molecules, such as $\mathrm{D}_{6}$, are not released into biogas and therefore remain in slurry [3]. The maximum siloxane concentration in the gas calculated from the Antoine equation depends on temperature [10]. Cyclic siloxanes are often suggested as a safer alternative for some uses, including $\mathrm{D}_{5}$ utilisation as replacement for perchlorethylene (tetrachlorethylene) in chemical cleaning processes [11. During biogas combustion 


\begin{tabular}{lcccccc}
\hline \multicolumn{1}{c}{ Title } & Formula & Abbreviation & $\begin{array}{c}\text { Molar } \\
\text { weight } \\
(\mathrm{g} / \mathrm{mol})\end{array}$ & $\begin{array}{c}\text { Vapour } \\
\text { tension } \\
\left(\mathrm{Pa}, 25^{\circ} \mathrm{C}\right)\end{array}$ & $\begin{array}{c}\text { Boiling } \\
\text { point } \\
\left({ }^{\circ} \mathrm{C}\right)\end{array}$ & $\begin{array}{c}\text { Solubility } \\
\left(\mathrm{mg} / \mathrm{l}, 25^{\circ} \mathrm{C}\right)\end{array}$ \\
\hline Hexamethylcyclotrisiloxane & $\mathrm{C}_{6} \mathrm{H}_{18} \mathrm{O}_{3} \mathrm{Si}_{3}$ & $\mathrm{D}_{3}$ & 222 & 1333.3 & 135 & 1.56 \\
Octamethylcyclotetrasiloxane & $\mathrm{C}_{8} \mathrm{H}_{24} \mathrm{O}_{4} \mathrm{Si}_{4}$ & $\mathrm{D}_{4}$ & 297 & 173.3 & 176 & 0.056 \\
Decamethylcyclopentasiloxane & $\mathrm{C}_{10} \mathrm{H}_{30} \mathrm{O}_{5} \mathrm{Si}_{5}$ & $\mathrm{D}_{5}$ & 371 & 53.3 & 211 & 0.017 \\
Dodecamethylcyclohexasiloxane & $\mathrm{C}_{12} \mathrm{H}_{36} \mathrm{O}_{6} \mathrm{Si}_{6}$ & $\mathrm{D}_{6}$ & 445 & 2.7 & 245 & 0.005 \\
\hline Hexamethyldisiloxane & $\mathrm{C}_{6} \mathrm{H}_{18} \mathrm{Si}_{2} \mathrm{O}$ & $\mathrm{L}_{2}, \mathrm{MM}$ & 162 & 4133.3 & 107 & 0.93 \\
Octamethyltrisiloxane & $\mathrm{C}_{8} \mathrm{H}_{24} \mathrm{Si}_{3} \mathrm{O}_{2}$ & $\mathrm{~L}_{3}, \mathrm{MDM}$ & 236 & 520 & 150 & 0.035 \\
Decamethyltetrasiloxane & $\mathrm{C}_{10} \mathrm{H}_{30} \mathrm{Si}_{4} \mathrm{O}_{3}$ & $\mathrm{~L}_{4}, \mathrm{MD}_{2} \mathrm{M}$ & 310 & 73.3 & 193 & - \\
Dodecamethylpentasiloxane & $\mathrm{C}_{12} \mathrm{H}_{36} \mathrm{Si}_{5} \mathrm{O}_{4}$ & $\mathrm{~L}_{5}, \mathrm{MD}_{3} \mathrm{M}$ & 384 & 9.3 & 220 & - \\
\hline
\end{tabular}

TABLE 1. Examples of siloxanes.

in gas burners or in engines, siloxanes oxidise to a very fine powder composed mainly of $\mathrm{SiO} 2$, which is precipitated on the internal metal surfaces of the combustion areas, for example on the walls of the pistons, heads of the cylinders, on the ignition coils, valves and other critical points [12].

There are many possibilities of how to remove undesirable silicon compounds from biogas; these methods are based on the adsorption or the adsorption principle, cryogenic elimination of siloxanes or microbial degradation of siloxanes [13, 14].

Adsorption is one of the best methods for siloxanes removal from biogas. For low polar siloxanes (they are insoluble in water and soluble in nonpolar organic solvents), the most suitable adsorbents are nonpolar carbonate adsorbents based on activated carbon. The results of another work demonstrate that activated carbon can adsorb approximately 1-1.5\% siloxane, by weight. 15. For separation of siloxanes, the required gas humidity is up to $30 \mathrm{rel} \%$. Therefore it is necessary to use equipment for biogas drying before the adsorption unit. Analysis of activated carbon saturated with siloxanes showed that $\mathrm{D}_{3}$ in the porous structure of the adsorbent partially polymerize to PDMS [3, 16]. According to the results of Schwegerkofler et al. [2], silica gel may also be used for adsorption of siloxanes. It is better to use it for the separation of siloxanes from landfill gas, because it has better affinity for L2 [15]. The second most common method used to capture siloxanes from biogas is based on absorption. The literature indicates that for the elimination of siloxanes a strong acid ( $\mathrm{pH} 1-3)$ or base $(\mathrm{pH} 10-12)$ can be used [3, 16]. The practical application of using sulfuric, nitric and phosphoric acids may cause an increased risk of corrosion of the equipment.

In practice, the higher efficiency of siloxanes removal can be proven by a system of deep gas cooling. Silanol (also present in the biogas) is much better soluble in the condensate and can therefore be removed more efficiently than other siloxanes 3 . By cooling the gas from the temperature of about $50{ }^{\circ} \mathrm{C}$ to about $5{ }^{\circ} \mathrm{C}$ almost $50 \%$ of siloxanes can be removed [17. Although there are indications that siloxanes are relatively stable to chemical and biochemical degradation, for the siloxanes removing anaerobic and aerobic biofilters (Popat Deshusses and [18]) were also tested. The results show that removal of $\mathrm{D}_{4}$ using microorganisms is inadequate because these organisms require a longer adaptation $\mathrm{D}_{4}$, to use it as a primary energy source. Research into $\mathrm{D}_{4}$ siloxane biodegradation also found its chemical decomposition at dimethylsilandiol PDMS (DMSD) followed by aerobic biodegradation DMSD to other compounds. Biodegradation DMSD is however very slow; only $2-4 \%$ degradation per month [18] was estimated.

Another possible method for siloxane removal is separation using a membrane process (selective siloxanes permeation and diffusion through the polymeric membrane material). Earlier experiments using a compact separation membrane have shown that the efficiency of siloxanes removal was higher than $80 \%$. Nevertheless, probably due to the relatively high investment and operating costs, this concept has been not further developed [19].

Decomposition of the siloxanes has also been studied using peroxidation, by using 3 peroxidation agents. Siloxanes removal efficiency ranged between 40-50\%. In the case of peroxidation using DMDO (dimethyldioxirane), even $85 \%$ of $\mathrm{D}_{4}$ [3] was eliminated.

Finally, ultrafiltration can be used as one of the other options for siloxane removal. Ultrafiltration removes contaminants on the basis of their size, and the typical molecular weight is in the range of 1000 to $100000 \mathrm{~g} / \mathrm{mol}$. Although siloxanes as much smaller molecules are probably captured by adsorption onto the filter cake formed during the process [3].

In technical practice, the best method for the removal of cyclic siloxanes is capturing them on a solid adsorbent, mostly on activated carbon, or absorption in a suitable solvent. These methods are often used in combination, in order to achieve a higher removal efficiency.

The experimental work was focused on the testing of varies types of activated carbon for siloxanes removal from biogas. 


\begin{tabular}{lcccc}
\hline Adsorbent & Type & Supplier & $\begin{array}{c}\text { BET-surface } \\
\left(\mathrm{m}^{2} / \mathrm{g}\right)\end{array}$ & $\begin{array}{c}\text { Total volume of } \\
\text { adsorption pores }(\mathrm{ml} / \mathrm{g})\end{array}$ \\
\hline AP 4-60 & Activated carbon & JaKo & 943.3 & 0.45 \\
Solcarb C3 & Impregnated AC & JaKo & 1165.4 & 0.62 \\
HS 10 & Activated carbon & Silcarbon Aktivkohle & 933.8 & 0.49 \\
CCA 4 & Impregnated AC & Silcarbon Aktivkohle & 914.7 & 0.5 \\
Picaclean & Activated carbon & Pica & 846.15 & 0.48 \\
Picactif & Activated carbon & Pica & 1270.3 & 0.59 \\
Oxorbon & Impregnated AC & Donau Chemie & 1322.9 & 0.74 \\
Desorex & Impregnated AC & Donau Chemie & 920 & 0.43 \\
AC 160 N & Activated carbon & Resorbent & 939.9 & 0.45 \\
MAC C6 D40 & Activated carbon & Resorbent & 977.2 & 0.56 \\
Sil 40 Extra & Activated carbon & Silcarbon Aktivkohle & 818.5 & 0.39 \\
Chezacarb & Active carbon black & Unipetrol RPA & 787.9 & 1.38 \\
\hline
\end{tabular}

TABLE 2. Basic information on the testing of adsorption materials.

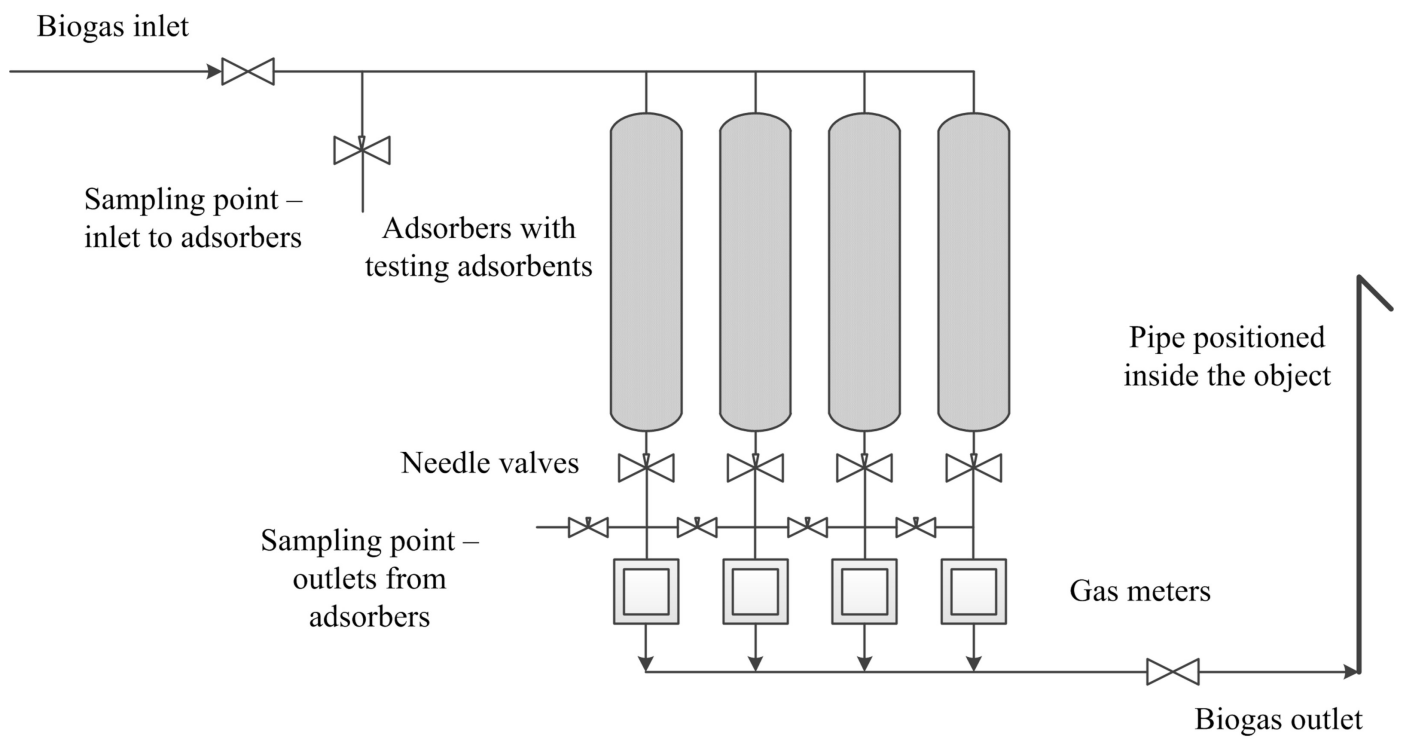

Figure 1. Apparatus for testing adsorption materials.

\section{EXPERIMENTAL}

\subsection{Materials}

Various carbonaceous adsorption materials were selected for adsorption tests focused on the removal of siloxanes from real biogas produced by anaerobic fermentation at waste water treatment plants. Basic information concerning the adsorbents selected for testing is given in Table 2

BET-surface and total volumes of the adsorption pores of the adsorbents were determined using Coulter SA 3100 analyzer by $77 \mathrm{~K}$; nitrogen was used as the adsorptive.

\subsection{Apparatus USED FOR The tests.}

The apparatus used for the tests allowed simultaneous testing of four adsorbents while using real biogas. The tests were carried out at the Central waste water treatment plant in Prague. The apparatus is schematically represented in Figure 1. The testing equipment comprises 4 adsorbents $1000 \mathrm{~mm}$ long and $40 \mathrm{~mm}$ in diameter, which are made of stainless steel. Gas is taken into the testing apparatus from a biogas pipe in the biogas treatment unit via a flexible Teflon pressure hose (Swagelok) with a diameter of $10 \mathrm{~mm}$. Behind each adsorber is a needle valve enabling the regulation of the flow of biogas through the adsorber. The biogas flow rate via individual adsorber was set to roughly $500 \mathrm{dm}^{3} / \mathrm{h}$. A sampling valve for biogas sampling is located on the pipe in front of the adsorption columns to determine siloxane content and other parameters of the biogas entering the adsorbers. Other sampling valves are located behind each adsorption column.

The tested adsorbents were loaded into the adsorbers and the weight of each adsorbent used for the testing was determined. The filled adsorbers were then connected to the testing apparatus and the flow rate of biogas through the adsorption towers was set to the required value. Biogas samples for determining siloxane content at the inlet to the apparatus and at the outlets of each adsorption column were taken at weekly intervals. 


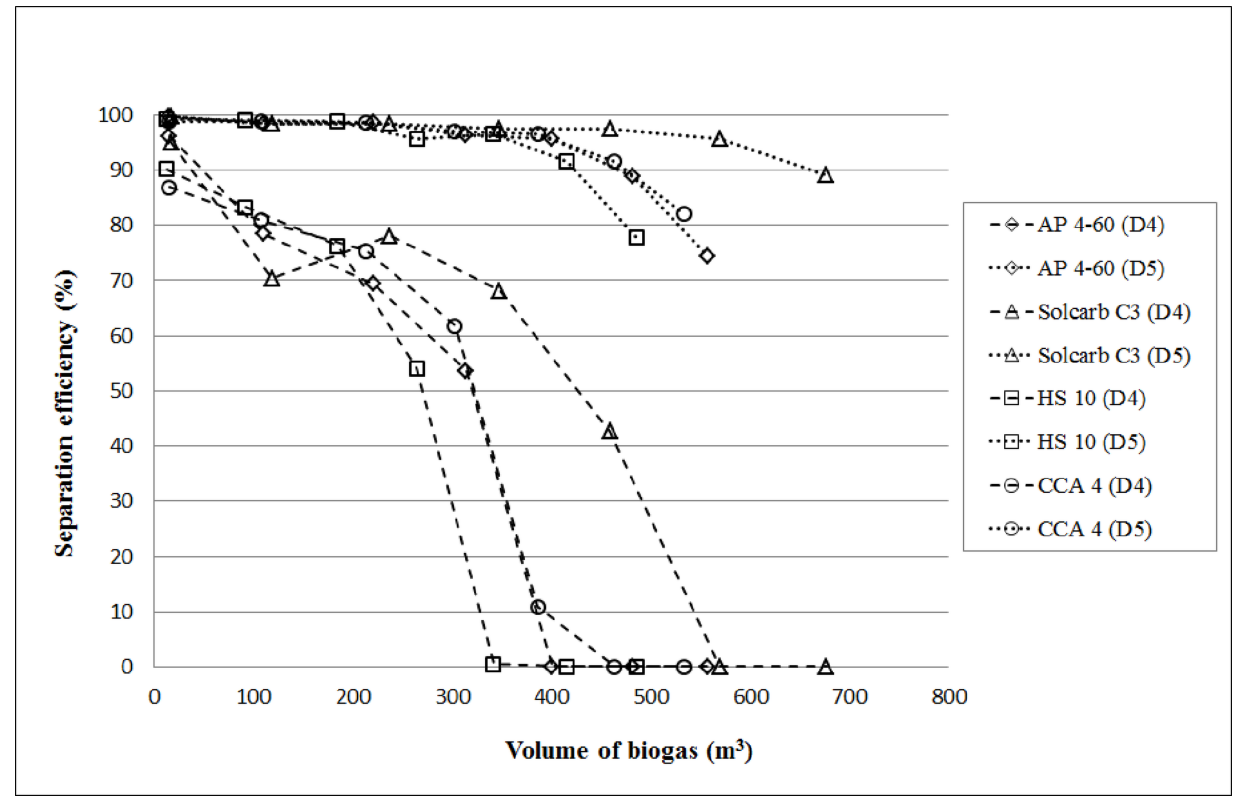

FIgURE 2. Efficiency of removal of monitored siloxanes $\left(\mathrm{D}_{4}\right.$ and $\left.\mathrm{D}_{5}\right)$ during the first phase.

\subsection{THE DETERMINATION OF ORGANOSILICON COMPOUNDS}

The determination of organosilicon compounds in biogas is based on capturing monitored substances in suitable absorption solvent. Siloxanes are retained from a known volume of biogas in an organic dissolving agent; the concentration of siloxanes in the solvent is determined by using a gas chromatography analysis equipped with a mass detector. From the used gas volume and the amount of dissolving agent it is then possible to calculate the content of siloxanes in the biogas. Toluene was chosen as a solvent for the capture of siloxanes from biogas because of its good siloxane solubility under normal conditions and its acceptable vapour tension.

When biogas samples are taken in order to determine the siloxanes, the dissolvent is filled in two washing bottles connected in series through which the biogas runs. A so-called freezing bottle is fixed in front of these two washing bottles to ensure the removal of humidity from the gas. All bottles are placed in a cooling pool filled with a blend of ice and $\mathrm{NaCl}$.

The optimal gas sampling speed is $1 \mathrm{dm}^{3} / \mathrm{min}$. It is necessary to let at least $100 \mathrm{dm} 3$ of the gas pass through the dissolving agent. The disadvantages of this method are the lengthy fieldwork required for taking samples and the necessity of cooling the sampling apparatus to a temperature close to $0^{\circ} \mathrm{C}$ during the entire measurement process. Cooling is used in order to reduce vaporization of the dissolving agent into the stream of biogas.

The absorption solution, which contains retained organic compounds of silica, is subsequently analysed using gas chromatography method with a mass detector, which enables the identification of individual organosilicon compounds and the specification of their concentrations in the absorption solution.

\subsection{Gas Chromatographic SYSTEM}

All analyses of absorption liquids containing the retained siloxanes were carried out on the gas chromatograph system HP 6890 - mass detector MSD 5973 (Hewlett-Packard, USA). CHEMSTATION software was used for operating the apparatus and also for evaluating the data. Using an auto sampler, the obtained samples were injected into the gas chromatograph; the volume injected was $1 \mu \mathrm{l}$. Helium was used as the carrier gas. To separate the mix, RESTEK RTX-1 column (100\% dimethylpolysiloxane) was used, 30 metres long and of 0.25 millimetres inner diameter. Stationary phase film thickness was $0.1 \mu \mathrm{m}$. The feed proceeded in a 1 : 5 distribution split. Molecular weights of the fragments were scanned in a range of $\mathrm{m} / \mathrm{z}$ from 10 to 400 . Ions 281 (characteristic ion for octamethylcyclotetrasiloxane) and 355 (for decamethylcyclopentasiloxane) were separated from the chromatograph of the total ion flow rate.

\section{Results AND Discussion}

\subsection{Removal of Siloxanes FROM BIOGAS}

The testing of selected adsorbents' capacity to retain siloxanes was carried out on an apparatus installed at the Central Waste Water Treatment Plant in Prague using real produced biogas. The testing process was divided into three consecutive phases. Different adsorption materials were tested in each phase; the testing procedure was identical in all individual phases. It was necessary to divide the testing into three consecutive phases due to the large number of adsorbent samples which were selected for testing.

Figure 2 shows the retaining efficiency of adsorbents tested in the first phase for the monitored siloxanes from biogas. It is clear from the graph that the efficiency of the retainment of heavier $\mathrm{D}_{4}$ molecules is 


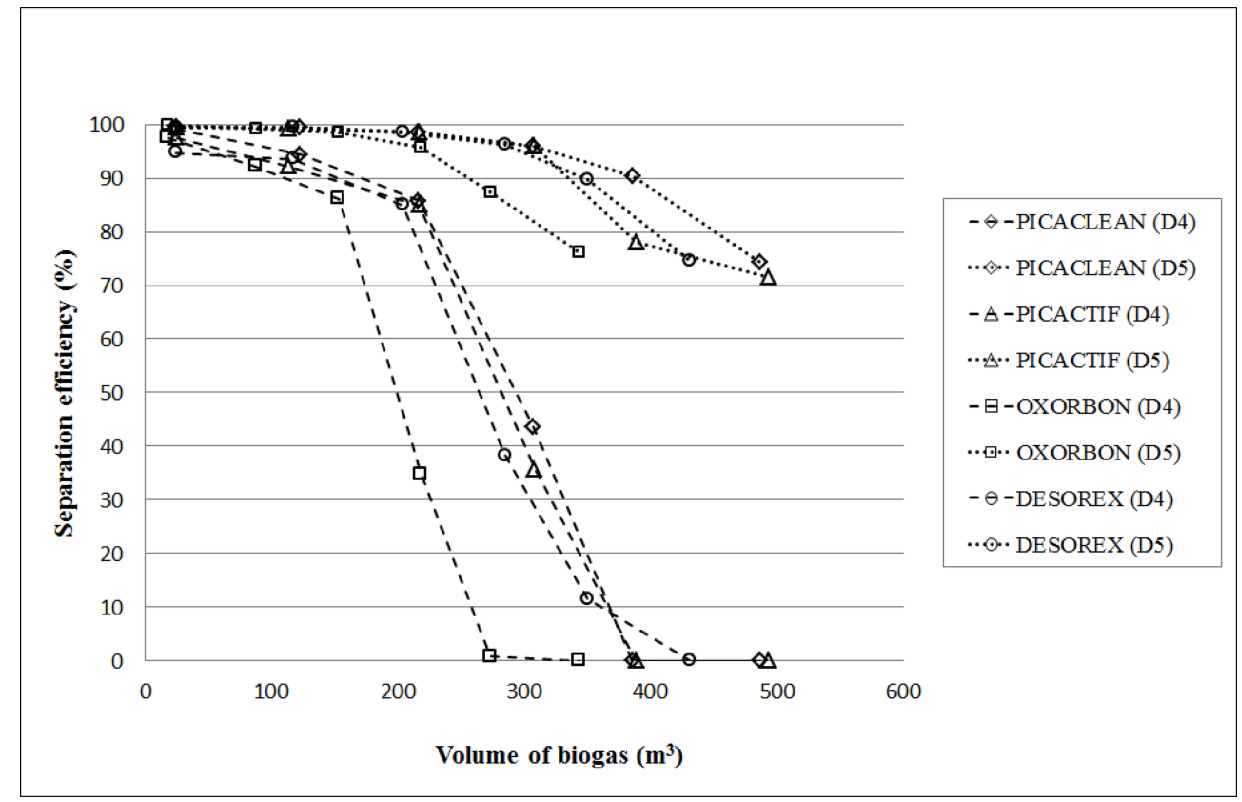

Figure 3. Efficiency of removal of the monitored siloxanes $\left(\mathrm{D}_{4}\right.$ and $\left.\mathrm{D}_{5}\right)$ during the second phase.

higher than that of the lighter $\mathrm{D}_{4}$ molecules. This may be explained by the fact that the so-called competitive adsorption process takes place on the surface of the adsorbents and the lighter $\mathrm{D}_{4}$ molecules are forced out by the molecules of other substances. The best siloxane adsorption capacity in this testing phase was shown by Solcarb C3.

Input and output concentrations of siloxanes in individual adsorption columns and the amount of biogas passed through the adsorption columns were the values used for calculating the adsorbed amount of siloxanes at each activated carbon sample. The adsorbed amount of siloxanes, related to the weight of the adsorbent filled in the relevant adsorption column was calculated by integrating the values gained in weekly measurements.

Figure 3 shows the efficiency of removal of the monitored siloxanes with the individual adsorbents tested in the second phase. Comparable results of siloxane retention were detected in the Picaclean, Picactif and Desorex adsorbents. The Oxorbon adsorbent shows a lower adsorption capacity for siloxanes depending on the amount of biogas that has passed through the column.

An X-ray fluorescent analysis showed the largest amount of silicon in the Picaclean adsorbent, as expected; in the mid and lower part of the adsorber the value was around $3 \mathrm{wt} \%$, which confirms a better expulsion of silicon compounds with adsorbed substances and a movement of siloxanes through the adsorption layer in the direction of gas flow.

The results acquired during the third phase of adsorbent testing are shown in Figure 4 Adsorbent Sil 40 Extra and activated carbon MC 6 AD showed a higher adsorption capacity, compared with the adsorbents AC $160 \mathrm{~N}$ and Chezacarb. The anomalies of some adsorbents resulted from a prolonged intermis- sion of measurement caused by unfavourable climatic conditions.

Activated carbon Chezacarb showed the highest saturation of adsorbents by siloxanes ( $6.26 \mathrm{wt} \%$ ); although it has to be pointed out that in comparison with the other samples of activated carbon samples used for testing, Chezacarb has approximately half the bulk density. In terms of silicon content in saturated samples, the adsorbents evaluated as best were AC 160 N, MC 6 AD and also Sil 40 Extra, whose average values reached approximately $1 \mathrm{wt} \%$. The content of silicon in saturated adsorbents did not exceed the results gained in the two measurements that preceeded.

The saturated sample of activated carbon AP 460 from the adsorption apparatus was extracted using hexane and toluene as solvents and the extracts were subsequently analyzed using GC-MS. In the extracts were found in the highest concentration cyclic siloxanes with 4, 5 and 6 structural blocks, and then tetradecamethylcycloheptasiloxane hexadekamethylcyklooctasiloxan or linear tetradecamethylhexasiloxan and hexadecamethylheptasiloxan in lower concentrations, as well as so far unknown eikosamethylcyklodekasiloxan, but in very low concentrations.

\subsection{UNDESIRABLE SUBSTANCES IN BIOGAS}

Thanks to the adsorbent analysis, the quantity of trapped sulfur and chlorine in the several profiles of adsorbent bed was also monitored. For reasons of safety, the arsenic content in the adsorbent was also monitored by disposal of saturated adsorbent. Almost double the sulfur content was found in the Solcarb C3 and CCA4 adsorbents. In such cases, the hydrogen sulphide is bonded on the adsorbent by chemisorption, in other cases the main part hydrogen sulphide is bonded by mechanism of physical sorption. The 


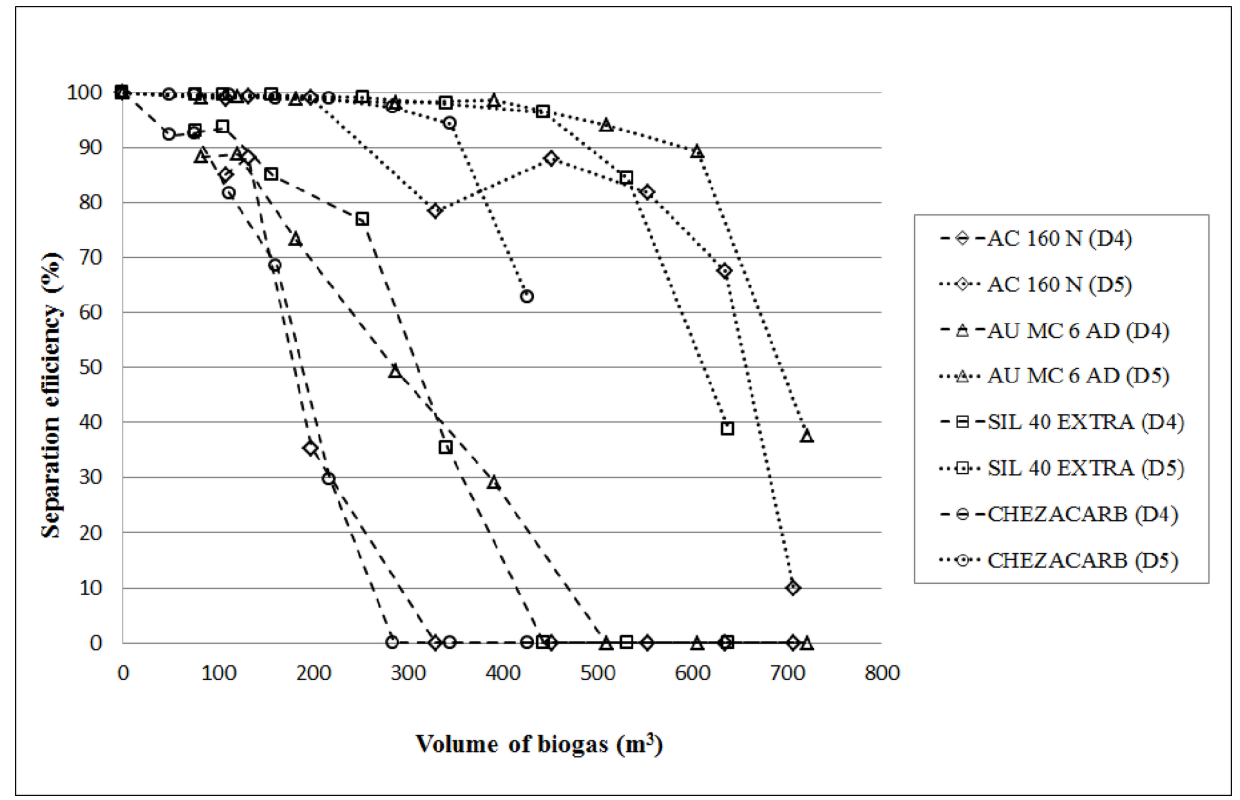

Figure 4. Efficiency of removal of the monitored siloxanes $\left(\mathrm{D}_{4}\right.$ and $\left.\mathrm{D}_{5}\right)$ during the third phase.

chlorine amount estimated in the analysed adsorbents ranged on average about $0.02 \mathrm{wt} \%$. Only in the case of impregnated carbon CCA4, which is primarily intended for removing sulfur compounds from gases, the amount of entrapped chlorine exceeded $0.12 \mathrm{wt} \%$. Equally important is the mapping of arsenic contents in the adsorbent; it is probably bonded in a similar way as hydrogen sulfide. Arsenic in biogas appears to be present as arsine $\left(\mathrm{H}_{3} \mathrm{As}\right)$. In the case of elevated arsenic amount, the loaded adsorbent is classified as hazardous waste. According to the results, arsine shows an analogy to the behavior of hydrogen sulphide, and the most captured arsenic was found in impregnated activated carbon Solcarb C3 and CCA4.

\subsection{EFFICIENCY OF SEPARATION}

Solcarb C3 proved to be the best adsorption material for siloxane retention from real biogas. Its saturation by siloxanes exceeded $5 \%$. As a priority, this adsorbent is used for the separation of sulphurous, nitrogenous and other substances from gases not containing oxygen. Its price is also higher when compared with the other adsorbents. The saturation by siloxanes of adsorption materials made by PICA was $3.9 \%$ for Picaclean and $3.7 \%$ for Picactif. Iodine impregnation of the remaining two adsorbents Oxorbon and Desorex did not have a positive effect on the separation of siloxanes from biogas. The adsorption material Chezacarb showed excellent sorption characteristics for the retention of all undesirable substances; saturation by siloxanes after the test was $6.3 \%$. The only disadvantage of this adsorbent is its low mechanical strength under pressure. The maximum values of mechanical strength under pressure are $10 \mathrm{~N} /$ piece for this adsorbent. To be suitable for use in real conditions, this value should reach at least $80 \mathrm{~N} /$ piece.

The effectiveness of siloxane separation from biogas for the tested adsorbents decreased with the increasing volume of purified biogas. At the volume of $500 \mathrm{~m} 3$ of passed-through gas, the only sample with an acceptable effectiveness of separation was Solcarb C3. Other adsorbents showed a decrease in sorption capacity for siloxanes after the passage of this amount of biogas. Figure 5 shows a comparison of the effectiveness of siloxane separation on tested adsorbents.

An important conclusion drawn from the testing is the finding that the siloxanes retained by the tested adsorbents were gradually forced out by other substances, which were adsorbed into the porous structure of the material more strongly than siloxanes. For this reason, siloxanes may at some point be leaving the adsorption column in concentrations which are higher than those at the inlet to the adsorption tower.

\subsection{ECONOMIC ASSESSMENT OF THE SUITABILITY OF USE OF THE INDIVIDUAL ADSORPTION MATERIALS}

Regarding the use of a selected adsorption material in industrial equipment, the economic balance of the used adsorbent is very important. The most suitable material is not the one which evidences the highest adsorption capacity for siloxanes, but the one with the highest adsorption capacity related to the price of the adsorbent fill necessary to load the adsorption tower of the operating equipment. An important piece of information is the percentage of saturation of the adsorbents by siloxanes related to $1 \mathrm{~kg}$ of adsorbent. The bulk density was determined for each of the used adsorbents. By using the above-mentioned adsorber volume in the calculation, the acquired values reflect the actual weight of the used material, which is important mainly with regard to the fact that the prices of adsorbents are calculated for their weight, not their volume. The obtained results clearly show that for 


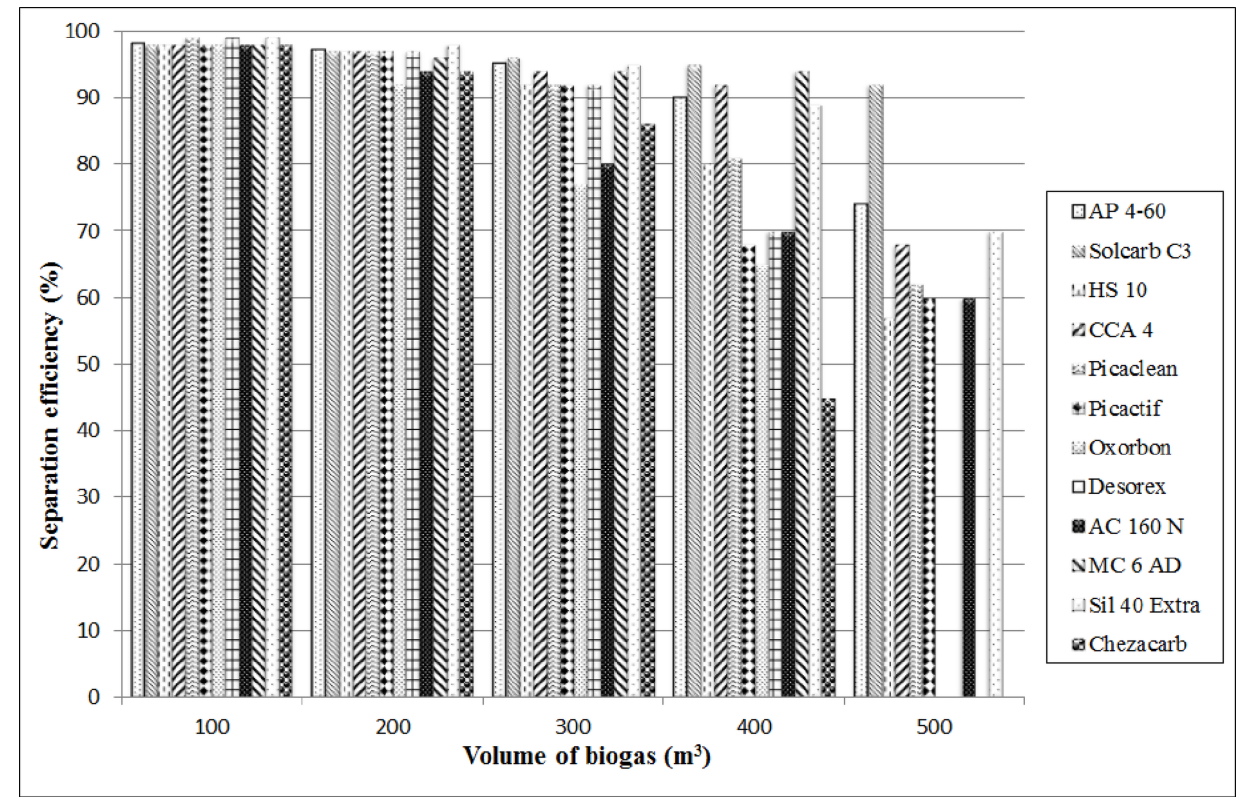

Figure 5. Comparison of the effectiveness of siloxane separation on the tested adsorbents.

the industrial use of some of the adsorption materials, the ratio of adsorption capacity for organosilicon compounds to the price of the adsorbent is very important.

\section{Conclusions}

12 commercially available activated carbon-based adsorption materials were tested at the pilot plant equipment using real biogas produced form sewage sludge, and their adsorption capacities for siloxanes were determined. The highest saturation by siloxanes of all tested samples (6.3 wt\%) was estimated by the Chezacarb adsorbent, which is an adsorbent based on active carbon black; followed by the activated carbon Solcarb (5.1wt\%). However, the individual tested adsorbents significantly differ in price (price range $1-5 € / \mathrm{kg}$ of adsorbent). The operational costs of adsorbents were therefore estimated and related to the removal of $1 \mathrm{~kg}$ of siloxanes from biogas.

It was discovered that the smaller $\mathrm{D}_{4}$ molecule, which is retained weakly, is relatively easily forced out by other substances. The second monitored siloxane, $\mathrm{D}_{5}$, has a larger and heavier molecule and is better retained in the porous structure of the adsorption material; its gradual forcing out happens more slowly in comparison with $\mathrm{D}_{4}$.

By the siloxane removal from biogas, other substances from the biogas are also adsorbed on the activated carbon. There are first of all high molecular organic compounds i.a. aliphatic hydrocarbons $\mathrm{C}_{11}-\mathrm{C}_{20}$ which cause the displacement of poorly adsorbed siloxanes. Also hydrogen sulfide and arsine are removed form the biogas. They are deposited at the impregnated activated carbons as sluphur and arsenicum, at other activated carbon samples they are poorly adsorbed by mechanism of physical sorption.

\section{REFERENCES}

[1] S. Rasi, A. Veijanen, J. Rintala. Trace compounds of biogas from different biogas production plants. Energy 32: 1375-1380, 2001.

[2] M. Schweigkofler, R. Niessner. Removal of siloxanes in biogases. J. Hazard. Mater. 83:183-196 B, 2001.

[3] A. Ajhar, M. Travesset, S. Yüce, T. Melin. Siloxane removal from lanfill and digester gas - A technology overview. Bioresour. Technol. 101:2913-2923, 2010.

[4] Y. Horii, K. Kannan. Survey of organosilicon compounds, including cyclic and linear siloxanes, in personal-care and household products. Arch. Environ. Contam. Toxicol. 55:701-710, 2008.

[5] R. Dewil R, L. Appels, J. Baeyens, A. Buczynska, L. V. Vaeck. The analysis of volatile siloxanes in waste activated sludge. Talanta. 74:14-19, 2007.

[6] A. Kochetkov, J. Smith, R. Ravikrishna, K. Valsaraj, L. Thibodeaux. Air-water partition constants for volatile methyl siloxanes. Environ. Toxicol. Chem. 20:2184-2188, 2001.

[7] R. Field, E. Olson. Surface-treatment chemismy in the manufacture of aerogels: computational modelling of cyclic and linear siloxanes. J. Non-Cryst. Solids. 285:194-201, 2001.

[8] R. Dewil R, L. Appels, J. Baeyens. Energy use of biogas hampered by the presence of siloxanes. Energy Convers. Manage. 47:1711-1722, 2006.

[9] K. Everaert, J. Baeyens. Catalytic combustion of volatile organic compounds. J. Hazard. Mater. 109:113-139, 2004.

[10] M. Palczewska-Tulinska, P. Oracz. Selected Physicochemical Properties of Hexamethylcyclotrisiloxane, Octamethylcyclotetrasiloxane and Decamtehylcyclopentasiloxane. J. Chem. Eng. Data 50:1711-1719, 2005. 
[11] M. J. Utell, R. Gelein, C. P. Yu, E. Geigel, A. Torres, D. Chalupa, F. R. Gibb, D. M. Speers, R. W. Mast, P. E. Morrow. Quantitative Exposure of Humans to an Octamethycyclotetrasiloxane (D4) Vapour. Toxicol. Sci. 44:206-213, 1998.

[12] M. Schweigkofler, R. Niessner. Determination of Siloxanes and VOC in Landfill Gas and Sewage Gas by Canister Sampling and GC-MS/AES analysis. Environ. Sci. Technol. 33:3680-3685, 1999.

[13] E. A. McBean. Siloxanes in biogases from landfills and wastewater digester, Technical note. Can. J. Civ. Eng. 35:431-436, 2008.

[14] R. Huppmann, H. Lohoff, H. Schröder. Cyclic siloxanes in the biological waste water treatment processDetermination, quantification and possibilities of elimination. Fresenius J. Anal. Chem. 354:66-71, 1996.

[15] E. Wheless, J. Pierce. Siloxanes in Landfill and Digester Gas Update. SWANA Landfill Gas Symposium, 2002.
[16] J. L. Pierce. Siloxane quantification, removal and impact on landfill gas utilization facilities, 8th Annual LMOP conference and project EXPO, 10-11 Jaunary 2005, Baltimore, Maryland.

[17] S. Saeed, S. Kao,G. Greaning. Comparison of Impinger and Canister Methods for the Determination of Siloxanes in Air, AWMA Symposium on Air Quality Measurement Methods and Technology, San Francisco, CA, November 13-15, 2002.

[18] S. C. Popat, C. Deshusses. Biological Removal of Siloxanes from Landfill and Digester Gases: Oportunities and Challenges. Environ. Sci. Technol. 22:8510-8515, 2008.

[19] A. Ajhar, T. Melin. Siloxane removal with gas permeation membranes, Symposium Euromembrane 2006, 24-28 September 2006, Giardini Naxos, Italy, Desalination 200 (2006), 234-234. 